\title{
Atualidade do pensamento social brasileiro
}

Recebido em

22/08/2011

Aprovado em 19/10/2011
Elide Rugai Bastos ${ }^{1}$ \section{de Sociologia da UNICAMP.}

do Departamento

Resumo Várias questões atualmente colocadas no âmbito das ciências humanas para o entendimento da sociedade foram, de vários modos, objeto da reflexão dos autores brasileiros ao longo dos anos: a problemática da emancipação, do direito à diferença, dos limites à liberdade, da definição da dignidade como projeto social, do reconhecimento, da exclusão/excludência, foram objetos recorrentes dos estudos sobre a formação nacional. Pretendo apontar, neste texto, como algumas reflexões dos anos 1950 e 1960 - brasileiras e latino-americanas - antecipam tais questões, mesmo sem terem desdobramento teórico sistemático.

Palavras-chave pensamento social brasileiro; subdesenvolvimento; marginalidade; mudança social

\begin{abstract}
Several themes that animate contemporary human sciences in their painstaking efforts to come to terms with society have been, in different ways, at the very center of the agenda of Brazilian social scientists. The following are some of such issues: emancipation, the right to difference, the limits to freedom, the definition of dignity as a social project, recognition, exclusion, among others, have all been subjected to the scrutiny of sociologists concerned with the issue of Brazilian national formation. This article intends to indicate some of the reflections that colored the 1950s and 1960s scholarly scene in both Brazil and Latin America, which anticipated most of such themes, despite their unsystematic theoretical treatments.
\end{abstract}

Keywords Brazilian social thought; underdevelopment; marginality; social change 
Respondendo à pergunta formulada por Lilia Moritz Schwarcz e André Botelho sobre como via o futuro da área do pensamento social brasileiro, apontei a contemporaneidade da temática que constantemente o animou (SCHWARCZ \& BOTELHO, 2011). Lembrei que várias questões atualmente colocadas no âmbito das ciências humanas para o entendimento da sociedade foram, de vários modos, objeto da reflexão dos autores brasileiros ao longo dos anos. Ou seja, a problemática da emancipação, do direito à diferença, dos limites à liberdade, da definição da dignidade como projeto social, do reconhecimento, da exclusão/excludência, foi objeto recorrente dos estudos sobre a formação nacional. A condição não democrática do país - colônia, escravidão, sucessão de ditaduras, extrema desigualdade na distribuição de bens - constituiu-se no cenário em que a solução dos impasses políticosociais se impunha à reflexão e exigia um olhar mais atento à realidade. É certo que o interesse e as possibilidades da discussão nos vários períodos foram desiguais. Nos últimos anos o retorno dos estudos sobre o pensamento social brasileiro e sua história permitiu que fossem retomados os debates, avaliados o seu alcance e limites, além de constatar seus efeitos.

Ora, as transformações mundiais colocam hoje aquelas questões sob outra ótica e conduzem à produção de diferentes categorias teóricas que buscam apreender os fenômenos, mas não podem desconhecer os caminhos trilhados pelas interpretações anteriores. É a partir dessa situação que a reflexão brasileira se insere, necessariamente, no debate internacional. Para ilustrar a hipótese levantada, pretendo apontar, neste texto, como algumas reflexões dos anos 1950 e 1960 - brasileiras e latino-americanas - antecipam questões atuais, mesmo sem terem tido desdobramento teórico sistemático.

\section{Necessidade de novos diagnósticos}

Quando Yeda Linhares e Francisco Carlos Teixeira da Silva avaliam o debate sobre a agricultura no Brasil do final dos anos 1950 e início dos 1960, apontam para a fragilidade dos projetos em discussão, debilidade esta que atribuem ao fato de os mesmos não estarem ancorados em bons diagnósticos sobre a realidade brasileira. Argumentam que a discussão sobre a 
mudança social, apesar do nível de politização que atingiu, foi limitada pelo desconhecimento da realidade efetiva e pelo caráter dogmático que marcava o debate(LINHARES \& TEIXEIRA DA SILVA, 1981).

É esse um dos temas da discussão que envolveu Florestan Fernandes e Guerreiro Ramos, no mesmo período, a propósito da situação, condições de produção e definição das tarefas da sociologia no Brasil. O sociólogo paulista insistia no fato de que só a aplicação de metodologia que possibilitasse o conhecimento da realidade e a reflexão sobre os mecanismos perpetuadores das relações sociais desiguais no Brasil permitiria uma solução política que associasse democracia política e desenvolvimento econômico. Essa perspectiva analítica era vista pelo cientista social baiano, atuando no Rio de Janeiro, como a possibilidade de um transplante teórico-metodológico que prejudicaria uma real visão sobre o país e, consequentemente, a elaboração de um projeto nacional autônomo. O debate coloca, em relação ao problema, dois argumentos não excludentes e não redutíveis, pois perspectivas importantes para a compreensão do país e do trabalho intelectual aqui realizado são colocadas pelos dois autores².

É certo que dificuldades de várias ordens impediam, naquele momento, que se fizessem estudos acurados sobre as mudanças em curso e os obstáculos à tomada de decisões que alterassem os perfis econômico, social, cultural e político do país. Florestan já apontara os limites do desenvolvimento da sociologia porque constrangida a pesquisas limitadas pela falta de financiamento de órgãos estatais (FERNANDES, 1976) ${ }^{3}$.

No mesmo momento, Costa Pinto desenhara, através de pesquisa financiada pela Capes ${ }^{4}$, a evolução dos estudos e cursos de ciências sociais no Brasil, apontando as dificuldades de sua consolidação e desenvolvimento. Embora mostrasse a existência de um novo impulso trazido pela preocupação de formação de especialistas para atuar no desenvolvimento da sociedade brasileira, indica restrições presentes no processo (COSTA PINTO, s/d).

A reflexão sobre o desenvolvimento da sociologia no Brasil e da temática que a constitui obrigaria a se fixar o contexto histórico e linguístico em que se efetua essa evolução. Sergio Miceli lembra que, no Brasil, "a história das Ciências Sociais constitui um aspecto do quadro de transformações por que passa o processo de diferenciação do sistema político em suas
${ }^{2} \mathrm{O}$ seminário realizado em outubro de 1959, promovido pelo CLAPCS, reuniu 60 cientistas sociais de várias especialidades, vindo de mais de 20 países - Américas do Sul, Central e do Norte e Europa. Foram apresentados e discutidos 43 trabalhos sobre a temática do desenvolvimento.

${ }^{3}$ Ver também BOCK (1980).

${ }^{4} \mathrm{~A}$ tese será conhecida como a afirmação da existência de dois brasis, pois já publicara os livros, Brésil e Os dois Brasis. 
vertentes pública e privada" (MICELI, 1989). Assim, para refletir sobre o período indicado estudado, seria necessário reconstruirmos o quadro econômico e político que comporta as mudanças propostas. Porém, num artigo limitado é difícil realizar essa tarefa, portanto partimos da suposição de que as linhas gerais desse pano de fundo são conhecidas. Se tomarmos como ponto de referência o pensamento sócio-político daquele momento, constatamos que a criação de inúmeras instituições, a ampliação das universidades e institutos de pesquisa alteraram o cenário dos anos 1950 e 1960. Lembrando o contexto léxico em que se funda, no Brasil, o debate do período, constatamos que conceitos como desenvolvimento, subdesenvolvimento, mudança social, marginalidade marcaram de modo amplo ou mais restrito as análises e estão ligados à condução política na qual se desenham os projetos nacionais. Mais ainda, tais conceitos aparecem de forma articulada, embora com sentidos diferenciados nos diversos autores e nas diferentes fases da história brasileira.

\section{Sudesenvolvimento/marginalidade}

O conceito marginalidade comportou vários conteúdos, respondeu a inúmeros problemas conjunturais ao longo da história da sociologia. Naturalmente, o tema, na maior parte das vezes, esteve associado à alternativa emprego/desemprego, sugerindo-se, em vários textos, que a solução para a questão residia na ampliação do e integração no mercado de trabalho.

A questão da marginalidade e a "necessidade" de fixação de um modelo sócio-econômico que servisse de gabarito para afirmar que um indivíduo, um grupo, uma região ou um país fosse considerado próximo ou longínquo a esse modelo, marcaram profundamente a produção intelectual dos anos 1950-60. Pela importância das questões que essa abordagem comporta, a definição da categoria marginalidade e do processo de marginalização envolve inúmeros confrontos entre os intelectuais. Exemplo das dificuldades que constituem a problemática encontra-se nos debates sobre o trabalho de Wright Mills (1959), apresentado no Rio de Janeiro, no seminário internacional "Resistências à mudança - Fatores que impedem ou dificultam o desen- 
volvimento"5, organizado pelo Centro Latino Americano de Pesquisas em Ciências Sociais - CLAPCS. Os objetivos desse encontro têm claramente um norte: trata-se de buscar conjuntamente - pesquisadores latino-americanos estudiosos do tema - a elaboração de uma sociologia do desenvolvimento que ampliasse o âmbito da discussão até então vigente, atrelada às propostas da Cepal. Estas, segundo os organizadores do seminário, propunham um projeto desenvolvimentista fundado em interesses gerais dos países e do continente americano. Assim, não enfocavam as questões que diferenciam regiões, países e grupos sociais. A comunicação de Wright Mills parte dessa crítica, provocando ampla aceitação ao apontar as limitações do emprego da expressão "o desenvolvimento", afirmando estar a mesma ancorada em modelo explicativo evolucionista característico do século XIX, o qual propõe dois pólos excludentes. Em outros termos, voltando a discussões correntes em sociologia, o pressuposto da noção de progresso, que se coloca como pano de fundo da maior parte dos conceitos de desenvolvimento ou mudança, levaria a uma polarização paralisante ${ }^{6}$. Assim, procura analisar as formas presentes no que considera os dois modelos paradigmáticos de industrialização - União Soviética, o comunista, e Estados Unidos da América, o capitalista - e o papel do Estado e da Sociedade na formulação e consolidação dos mesmos. Afirma não acreditar que esses modelos levaram à construção de uma verdadeira sociedade democrática.

Exclui a possibilidade, para os países subdesenvolvidos (uso a expressão empregada pelo autor no texto) de seguir qualquer um desses modelos, pois, não pensa ser "verdadeira a afirmação de que a totalidade da população dos países subdesenvolvidos deva tornar-se industrializada" (MILLS, op. cit., p. 284). Desse modo, para o autor, as sociedades subdesenvolvidas, ao colocarem em outro patamar o problema, podem encontrar formas de organização, instrumentos de participação, "que tornem possível uma variedade de modos de ser, de estilos de vida, talvez nunca vistos na história humana" (idem, p. 286). Esse processo levaria ao surgimento de outro tipo humano que encontraria seu fundamento não nos modelos existentes, mas nas singularidades presentes na própria sociedade.

Aqui se coloca, para Mills, um problema político fundamental: como alcançar os objetivos acima propostos? A partir de agendas políticas for-
${ }^{5}$ Resumo dos debates. In: Anais, op. cit., p. 297.

${ }^{6}$ Consultar ARRUDA (2001) 
${ }^{7} \mathrm{~A}$ tese será conhecida como a afirmação da existência de dois brasis, pois já publicara os livros, Brésil e Os dois Brasis. muladas por grupos dirigentes? Ou seguindo-se formas geradas por um sistema democrático com participação direta da população? É exatamente a resposta que encaminha a essas alternativas que se constitui no eixo do debate. Retomando a afirmação de Jacques Lambert sobre a existência, na América Latina, de sociedades dualistas, apresentada no mesmo seminário (LAMBERT, 1960)7 , busca mostrar as dificuldades de se encontrar uma solução democrática para o encaminhamento da questão. Afirmando a permanência de fortes setores tradicionais nessas sociedades, com interesses opostos ao da modernização, gera-se um colonialismo interno que impede soluções políticas de caráter nacional. As sociedades subdesenvolvidas "são, muitas vezes estados, mas não realmente nações" (MILLS, op. cit., p. 285). Desse modo, sugere que a reflexão sobre mudança social deva ancorar-se na pergunta: existem condições de homogeneidade econômica, social, política e cultural que permitam, nos países da América Latina, que se encaminhe uma solução democrática para a elaboração de um projeto de desenvolvimento? Segundo o autor, a pergunta coloca ao cientista social um dilema moral, face ao qual se encontra, naquele momento: definir qual "a distinção entre 'em que o homem está interessado' e 'quais são os interesses do homem"' (idem, p. 286). Aqui está colocada, além da questão sobre o perfil do Estado e o tema do planejamento, a definição do papel do intelectual na sociedade, ou mais exatamente, nas sociedades periféricas, temática central principalmente nos anos 1960-70, problema que não abordarei neste texto.

Os debates sobre as colocações de Wright Mills envolveram principalmente os sociólogos Octavio Ianni, Enrique Arboleya, Pablo Gonzalez Casanova e Florestan Fernandes (obedeço à ordem da colocação das perguntas). Embora de acordo em relação à necessidade de ampliação da discussão sobre o desenvolvimento, incluindo a sociologia como campo importante, a discordância diz respeito, principalmente, ao diagnóstico feito pelo sociólogo norte-americano.

Ianni, da Universidade de São Paulo, aponta afirmações de Mills que Ihe parecem contraditórias, "a asserção que a criação do terceiro tipo de homem, diferente do americano e do soviético, teria condições para se afirmar na América Latina e, de outro lado, a afirmação de que nos países 
subdesenvolvidos a democracia e o desenvolvimento econômico são incompatíveis". Enrique Arboleya, da Universidade de Madrid, relembra que o debate sobre o desenvolvimento na sociedade daquele momento comportou posições críticas e que, no capitalismo, existem muitos elementos planificados e racionalizados, e não apenas no modelo comunista. Casanova, do México, criticou a afirmação "de que a democracia não é o meIhor caminho para o desenvolvimento, (...) [pois] quando um país tem que se defender da penetração de países mais desenvolvidos ou quando tem que melhorar suas relações de intercâmbio com países avançados é indispensável o fortalecimento do governo democrático" (idem). Fernandes, da Universidade de São Paulo, discorda da análise feita por Mills tanto sobre a URSS, quanto sobre os USA, argumentando sobre a não homogeneidade interna dos sistemas, lembrando a presença tanto da diversidade quanto da desigualdade em ambos, o que se apresenta como forte traço característico dos países subdesenvolvidos (op. cit., p. 298).

Para ilustrar o sentido das discussões, no caso de Florestan Fernandes, a razão de sua oposição teórica (não apenas sobre o diagnóstico a respeito de URSS e USA) encontra-se no texto apresentado ao mesmo seminário (FERNANDES, 1960a). Entendendo o desenvolvimento como um conjunto de formas interativas em uma sociedade, percebe o conceito como inclusivo compreendendo mudanças decorrentes de diferenciação estrutural e da reintegração funcional de sistemas sociais concretos. "Por isso, ele abrange os aspectos dinâmicos das alterações da estrutura, da organização e dos mecanismos de controle de dado sistema social em certo lapso de tempo" (idem, p. 220). Nesse sentido, nega a possibilidade de se pensar um projeto de mudança a partir de uma concepção de ordem social preestabelecida, aplicável a todas as sociedades. Lembrando as dimensões temporal e espacial de qualquer intervenção na realidade, restabelece o conteúdo histórico do conceito. A partir dessa ótica torna-se inoperante o conceito de marginalidade, uma vez que Florestan recusa a existência de um modelo prévio de organização da sociedade.

$\mathrm{Na}$ exposição dessa tese, que ganhará força em sua obra posterior principalmente na exposição do que conceberá como desenvolvimento desigual e combinado -, lembra a importância das diferentes esferas da
${ }^{8}$ Resumo dos debates. In: Anais, op. cit., p. 297. 
${ }^{9}$ Vários autores indianos têm se dedicado à questão. Vide, por exemplo, CHARTTERJEE (1993) sociedade, econômica, social, política e cultural. Acentua, ainda, a interdependência dessas esferas, isto é, a inserção econômica, o pertencimento social, a participação política e a assimilação da cultura fazem parte de um único processo social no qual um elemento atua como reprodutor do outro. Chamo a atenção, sem desenvolver aqui o tema, para a importância do elemento cultural - usará o conceito de demora cultural -, que nesse autor não tem o sentido de atraso, como aparece em várias propostas dos organismos internacionais voltados à intervenção na direção do desenvolvimento econômico. O tema do respeito às formas culturais na definição dos projetos de desenvolvimento quase não é abordado pelos autores naquele momento, pois a diversidade, se não considerada como um mal, é vista, pelo menos, como um exotismo. Hoje, sabemos, o respeito à diversidade cultural tornou-se elemento fundamental para a reflexão sobre a questão nacional, a questão social e o desenvolvimento ${ }^{9}$.

Além de apontar a restrição da própria formulação de desenvolvimento presente em diversas apresentações, Florestan lembra o limite metodológico presente na caracterização de tipos sociais, que é aplicada pelos analistas na descrição de regiões consideradas atrasadas e/ou modernas. Em outros termos, critica a tese sobre caráter nacional, lugar comum nas décadas anteriores, a qual ainda persiste em várias das análises sobre o desenvolvimento. A mais importante advertência feita pelo autor nesse artigo é a que se refere à dimensão ética envolvida na discussão.

Por motivos diferentes, os alvos do desenvolvimento social, valorizados tanto nos 'países adiantados' (...) quanto nos 'países subdesenvolvidos' (...) incentivam mudanças sociais indiretamente subordinadas aos interesses e valores sociais das camadas dominantes na estrutura de poder. Medidas formuladas em nome dos 'interesses da Nação' raramente correspondem, de fato, às necessidades vitais da comunidade como um todo. No entanto, tais medidas contam, em média, com as pressões abertas ou dissimuladas da propaganda organizada. (FERNANDES, op. cit., p. 224)

É importante assinalar como esse elemento ético é central no debate 
contemporâneo, principalmente quando os problemas da identidade e possibilidade de reivindicação de direitos são abordados pelas teorias do reconhecimento. É evidente que não estou sugerindo que o avanço da análise a que se chegou foi desenvolvido por Florestan Fernandes. Somente quero apontar dois pontos. Primeiro: a teoria crítica sempre teve a "orientação para a emancipação que (...) exige também que a teoria seja expressão de um comportamento crítico relativamente ao conhecimento produzido e à própria realidade social que esse conhecimento pretende apreender" (NOBRE, 2003, p. 9). Segundo: o reconhecimento do projeto emancipatório como eixo da modernidade, portanto como referência central em qualquer projeto de mudança social, é parte constitutiva da obra do sociólogo paulista, desde seus primeiros trabalhos. Em 1945, por exemplo, lembra aos intelectuais a necessidade de democratização da cultura como um momento constitutivo da democracia política e da democracia econômica (FERNANDES, 1945) ${ }^{10}$. Portanto, a orientação para a emancipação sempre fez parte da reflexão de Florestan Fernandes sobre mudança social"1.

Embora ilustre com apenas uma polêmica, quero apontar como o seminário internacional do CLAPCS, realizado em 1959, coloca em debate não apenas projetos de desenvolvimento em confronto, mas, principalmente, visões sobre o papel dos intelectuais e da sociologia. Mais ainda, mostra os primeiros passos para uma reflexão sobre categorias analíticas, colocação possível pela situação vivida pelos países da América Latina, processo abortado pelos acontecimentos políticos que resultaram em restrição à continuidade do pensamento e formulação de ideias centrais para a compreensão da "condição periférica".

É interessante lembrar o comentário feito por Costa Pinto, na apresentação dos Anais do seminário, comentando o teor, não só teórico como político, das discussões.

O fecundo resultado que daí adveio foi o alto nível científico das discussões, a seriedade e a multiplicidade de ângulos pelos quais a problemática do desenvolvimento foi estudada e, sobretudo, a enorme distância que logo se estabeleceu entre a sociologia do desenvolvimento nacional, que aí de fato foi debatida por inte-
${ }^{10}$ Ver também, do mesmo autor: "Existe uma crise da democracia no Brasil?" (1960)

${ }^{11}$ Consultar ARRUDA (2001) 
ligente e eficiente grupo de cientistas sociais - e a abordagem ideológica do problema que, em muitos países da região, certos grupos de pressão ruidosamente procuram apresentar como análise séria e científica dos problemas do desenvolvimento. (COSTA PINTO, 1960)

\section{Marginalidade: diferentes compreensões}

Como já foi dito anteriormente, o conceito de marginalidade comporta várias dimensões e compreende vários aspectos muitas vezes em oposição. Essa oposição está presente em quase todas as definições, por incorporar uma visão dualista, em que arcaico e moderno, velho e novo colocam-se como dicotomias; em geral argumenta-se que o elemento tradicional deva ser superado. Levantei a hipótese de que, nos debates do período compreendido entre 1950 e 1970, o elemento cultural nessas definições, fundamental para a compreensão da diversidade, é valorizado negativamente por grande parte dos autores. Diante das questões sociais hoje presentes, a esfera cultural tornou-se central na análise sociológica, valorizando-se uma categoria importante na área - socialização - a qual, durante largo período, foi quase esquecida pela sociologia. Assim, cabe aqui retomar, brevemente, os diferentes conteúdos dessas definições.

Várias conotações sobre marginalidade aparecem nos textos do período estudado: marginalidade estrutural, marginalidade como resíduo do desenvolvimento econômico, marginalidade e demora cultural, etc. Manoel T. Berlinck (1975) analisando a questão urbana, apresenta uma tipologia das principais definições presentes naquele momento. O cenário desenvolvimentista, desde os anos 1950, levou a que, rapidamente, se colocasse, como modelo de inserção da população latino-americana, o progresso gerador de empregos, e os setores que não se integrassem nesse gabarito precisavam ser explicados pelas ciências sociais. Tratava-se de um quadro eufórico onde "não havia lugar para a existência de favelas e cortiços que, no entanto, teimavam em existir no cenário das mesmas cidades - como São Paulo e Rio - onde 'o progresso' ocorria. Como 'explicar' essa situação 
'paradoxal'?" O conceito de marginalidade com uma definição espacial, foi a resposta encontrada e "adotada por técnicos de planejamento urbano e desfavelamento e foi vista como um mal transitório, produto de um desajuste circunstancial no processo de desenvolvimento urbano" (idem, p. 14).

O autor aponta as várias críticas e pesquisas que questionaram essa interpretação, indicando a não homogeneidade da população residente em favelas, suas diferentes inserções na sociedade inclusiva, a pluralidade de comportamentos políticos, etc. Aponta, ainda, a noção de marginalidade fundada na ideia de passividade. Tal concepção atribui uma ambivalência ao indivíduo que se encontra "entre duas culturas", enfrentando, nesse caso, problemas de integração. Tal posição, bastante difundida nos países latino-americanos, deve-se principalmente, e Berlincki lembra essa influência, às análises difundidas pela DESAL (Centro para el desarrollo económico y social de América Latina). Trata-se de uma tese que parte da afirmação da existência de uma dualidade estrutural, expressa na dicotomia arcaico/moderno, velho/novo, como já foi apontada acima.

Lendo um dos mais difundidos textos da DESAL, América Latina y desarrollo social, encontramos várias passagens que afirmam essa posição.

A primeira forma de marginalidade - a mais corrente e visível - se refere ao sentido passivo da participação. Podemos dizer de um homem ou de um grupo de homens constitutivos de uma base societária da qual estão marginalizados, quando não recebem, não participam da finalidade, das normas, dos valores, dos meios nem da divisão de trabalho nessa base social.

(...) É indubitável que o mais importante e criador dos sentidos do termo participação é o dinâmico, da colaboração e da ação espontânea. Somente quando constatamos que existem homens que em suas consciências e vontades não contribuem à definição da finalidade [estabelecida pela sociedade]; não cumprem com as normas por ela estabelecidas; que não aderem às ideias e valores próprios da unidade, homens que não têm acesso aos meios que visam o alcance dos objetivos e aqueles aos quais não se atribui nenhum papel, tarefa ou função específica, somente 
${ }^{12}$ Inúmeras críticas já foram feitas à formulação do antropólogo Oscar Lewis, o que me libera da necessidade de retomálas aqui. Ver, por exemplo, STAVENHAGEN (1974) e CASANOVA (1969). então podemos falar de marginalidade. (DESAL, 1966)

A longa citação justifica-se porque mostra os dois elementos que quero apontar como limites analíticos presentes nessa tese: de um lado, a afirmação da existência de um dualismo estrutural; de outro, a indicação de que a situação de marginalidade é uma "escolha" do homem ou do grupo.

$\mathrm{Na}$ mesma linha da marginalidade fundada na passividade, Berlinck analisa as teses apoiadas na afirmação de Oscar Lewis sobre as características da "cultura da pobreza". Embora a definição da cultura da pobreza compreenda a noção de adaptabilidade, o que ultrapassa os limites colocados pela formulação da DESAL, Lewis a apresenta através de uma dicotomia: de um lado, trata-se de um modo de adaptar-se à sociedade envolvente; de outro, é uma forma de os pobres reagirem à sociedade capitalista, individualizada e organizada em classes sociais. Sendo reativa, supõe a presença da consciência da situação diferenciada. A valorização dos elementos culturais marcadores dessa diferença, a manutenção dos mesmos e sua transmissão através do processo de socialização tornamse, segundo o autor, obstáculos psicológicos para que as crianças estejam preparadas para se beneficiarem das condições de mudança e aproveitarem das oportunidades que estas poderiam acarretar. Uma das principais críticas que foram dirigidas a essas teses aponta a fragilidade da ideia de autonomia da cultura, proposição que está quase sempre presente nas discussões sobre marginalidade.

A cultura da pobreza produz, segundo Lewis, a incapacidade de organização em relação à luta para superar a condição em que se encontram os pobres. Em outros termos, a privação e a exclusão conduzem à configuração de traços que reforçam a marginalidade e a dependência, gerando passividade comportamental' ${ }^{12}$.

Nas discussões dos anos 1960, a marginalidade é vista também como resíduo no desenvolvimento econômico, pois esse processo ocorreria paulatinamente de modo a se tornar incapaz de beneficiar toda a população de uma sociedade ao mesmo tempo. "Assim, o processo de desenvolvimento coexiste com uma 'população marginal ao desenvolvimento' que, eventualmente poderá ser beneficiada pelo processo, se ele subsistir"(BERLINCK, 
op. cit. p. 20). Dessa ótica, a “camada marginal” acaba por ser vista, não só pelos analistas, mas também apreendida pelos especialistas em políticas públicas como um setor para o qual resta apenas a "espera" do encaminhamento promissor de um projeto desenvolvimentista nacional. Cito:

Os marginais são (...) aqueles que 'não pertencem'... estão localizados na parte inferior da escala social, ou melhor fora dela. Pode-se dizer que não estão social e economicamente integrados a uma sociedade, a um sistema de classes, já que não pertencem a um sistema econômico (...)não são ninguém, não fazem mais que estar, povoar um pedaço de terra, que é terra de ninguém. (VEKEMANS \& FUENZALIDA, 1969, p. 44) 13

A marginalidade é também apresentada como oponente de integração social. Aníbal Quijano (1966), representante dessa corrente, desenvolve uma visão mais sistemática que as anteriores, descrevendo aspectos caracteristicamente diferenciados, referidos concretamente a cada sociedade e não definidos abstratamente. Desse modo, "a marginalidade é um problema inerente à estrutura de qualquer sociedade e varia em cada momento histórico". Diferenciando integração da sociedade e na sociedade, Quijano confere à noção "um valor heurístico, na medida em que indica as limitações dos elementos institucionais básicos de cada estrutura" (BERLINCK, op. cit., p. 21). Sem entrar nos pormenores da argumentação de Quijano, pode-se criticá-la, por reproduzir, a partir de outra ótica, o pressuposto do dualismo estrutural.

Em texto que analisa parte da obra de Costa Pinto, Gláucia Villas Bôas (2005) aponta para o mito da ambiguidade que se encontra atrás da maior parte dos debates sobre a instauração da ordem moderna, igualitária e competitiva no Brasil, eixo das discussões sobre a marginalidade. Em outras palavras, mostra que as perspectivas que veem o atraso como patológico reproduzem "uma visão normativa da sociedade e, consequentemente, rejeitam o postulado de que a sociedade se faz através de conflito de diferentes ordens e valores predominando uns sobre outros" (op. cit., p. 81). Nessa colocação está clara a crítica à convergência de grande parte das análises à tese da
${ }^{13}$ Ver também a crítica de Rodolfo STAVENHAGEN, op. cit., feita a essa proposição. 
${ }^{14}$ Ver VILLAS BÔAS (2006)

${ }^{15}$ Consultar, especialmente, FERNANDES (1974), onde estão reunidos artigos escritos entre 1946-59.

existência de interesses gerais, que são definidos como interesses nacionais, como se a sociedade brasileira fosse homogênea e se constituísse em um espaço social em que as condições sócio-econômicas-políticas-culturais para a competição se apresentassem de forma igual para toda a população. Mais, como se as diferenças que definem a marginalidade fossem de grau e não assentadas na existência de interesses conflitantes.

Não foi apenas a relevância do conflito que ocupou o sociólogo no seu empenho em legitimar uma perspectiva de interpretação sociológica das mudanças. Acreditando que somente o estudo da dimensão sociológica do agir humano poderia contribuir para as transformações e contrário a toda e qualquer 'ideologia' que pudesse obscurecer aquela contribuição, Costa Pinto posicionou-se contra o nacionalismo, que se incorporara em definitivo ao vocabulário político da época, qualificando, sobretudo, o desenvolvimento de 'nacional'. Pode-se bem imaginar as querelas e dificuldades que teve, sobretudo no Rio de Janeiro, frente à vigorosa produção e o debate de idéias produzido pelo ISEB. (op. cit., p. 84)

Não vou desenvolver aqui as considerações feitas sobre o alcance e os limites do conceito de marginalidade estrutural, porque já estão bem formulados no artigo citado e concordo totalmente com elas. Passo, pois, a retomar o tema da marginalidade a partir do ângulo da mudança social, enfoque central no período estudado.

\section{Mudança social}

Para ilustrar o debate, embora este abranja posições diferenciadas entre os diversos autores ${ }^{14}$, recorro aos argumentos apresentados por Florestan Fernandes ${ }^{15}$. Esse autor mostra que várias questões importantes para a reflexão sociológica referente à questão da desigualdade estão presentes, se não explícita, pelo menos implicitamente, em textos dos anos 1940, antes de se tornarem centrais nos anos 1950. 
Por que o sociólogo, numa sociedade como a nossa, volta-se com tanta insistência para os problemas de mudança? Quais são as características da mudança numa sociedade como a brasileira? Por que o controle da mudança é tão importante para o poder politico das classes dominantes? (...) [essas perguntas] precisam ser consideradas em conjunto e tomadas não como 'foco de referência', mas como o ponto de partida de qualquer discussão sociológica crítica e realmente explicativa. (FERNANDES, 1974, p. 22)

Retomando a afirmação dos limites à homogeneidade social resultado da herança colonial, já exposta em trabalhos anteriores e que será aprofundada posteriormente, desenvolve a tese da incompletude da revolução burguesa no Brasil, que coloca o analista frente a uma realidade diferenciada em relação aos países centrais.

Isso implica em romper com o resíduo naturalista implícito na idéia de que o regime de classes surge da mesma maneira, funciona do mesmo modo e produz os mesmos resultados onde quer que ele apareça. (...) [assim] os cientistas sociais têm de operar, tanto descritiva quanto interpretativamente, com uma heterogeneização máxima dos fatores propriamente estruturais e dinâmicos da diferenciação social. (idem, p. 25)

Mostra, ainda, como a combinação das duas heranças - colonial e escravista - opera na direção da constituição de uma distância social que não é apenas quantitativa - de poder econômico, político e social - mas que está enraizada profundamente na cultura.

Aquele padrão [colonial e escravista] compatibiliza a coexistência da tolerância e até da cordialidade com um profundo desdém elitista por quem não possua a mesma condição social. O que faz com que aquilo que parece 'democrático' na superfície, seja de fato 'autoritário' e 'autocrático', em sua essência. Esse pata- 
mar psicossocial das relações humanas é a nossa herança mais duradoura (e, ao mesmo tempo, mais negativa) do passado colonial e do mundo escravista. (idem, p. 33)

Aponta para o fato de a mudança social estar constrangida pela condição "fechada" da ordem social competitiva a qual se esvazia como fator histórico-social, "tornando-se rígida ou inerte principalmente para os interesses de classes que não coincidem com os dos 'donos do poder'. Assim, ela não se transforma em "fonte das correções de tendências antidemocráticas e antinacionais", pois "funciona como uma fonte de perpetuação indefinida de fortalecimento de tais tendências" (idem, p.147-148).

Não quero alongar-me na exposição dos argumentos do autor, porém, o que me interessa é chamar a atenção para sua proposta analítica em relação à questão da marginalidade e da exclusão. A preocupação se desloca para o processo e não se fixa apenas na situação de exclusão; preocupa-se com o processo de excludência. Na mesma tradição de análise, José de Souza Martins chama a atenção para o problema, atualizando-o. Mostrando que existe uma fetichização do termo exclusão diz:

(...) existem vítimas de processos sociais, políticos e econômicos excludentes; existe o conflito pelo qual a vítima dos processos excludentes proclama seu inconformismo, seu mal-estar, sua revolta, sua esperança, sua força reivindicativa e sua reivindicação corrosiva. Essas reações, porque não se trata estritamente de exclusão, não se dão fora dos sistemas econômicos e dos sistemas de poder. Elas constituem o imponderável de tais sistemas, fazem parte deles, ainda que os negando. As reações não ocorrem de fora para dentro; elas ocorrem no interior da realidade problemática, 'dentro' da realidade que produziu os problemas que as causam. (MARTINS, 1997, p. 14)

Assim, o caminho de compreensão do processo de excludência, já presente em algumas críticas às definições de marginalidade expressas nos anos 1950-60, apontam para o reconhecimento da diversidade como 
elemento básico dos fundamentos de uma sociedade democrática, como muitas das novas propostas teóricas na área de ciências sociais procuram demonstrar. Ou ainda, que os chamados "marginais" são componentes da sociedade considerada como um todo, assumindo a função, independentemente de sua vontade, de reprodução das tendências antidemocráticas que lhe são constitutivas. Mais, na aparência, a ordem social competitiva está "aberta"para toda a população, escondendo a desigualdade de condições de competição. Se, naquele momento, o argumento fica condicionado à constatação, tanto pelos limites internos das análises como pelas constrições políticas, hoje várias vertentes teóricas se abrem para novas proposições. Trata-se, evidentemente, de uma hipótese que só o desenrolar da reflexão poderia confirmar.

Do ponto de vista metodológico, reabre-se uma velha questão: a partir da "periferia" do sistema social (e não apenas territorial), onde os conflitos sociais se apresentam em sua pluralidade, o analista encontra-se numa perspectiva que lhe permite visualizar melhor os problemas, o que nem sempre resulta na ampla sistematização dos mesmos ${ }^{16}$. Trata-se de mais uma possibilidade a ser levada em consideração para se refletir sobre o lugar do pensamento social brasileiro no quadro geral das ciências sociais.

Resumo: O artigo procura apontar como as temáticas da marginalidade e da exclusão, que se desdobram nas análises sobre o mundo rural e o urbano no Brasil, a partir dos anos 1950, fundam outras indagações no mundo contemporâneo. Isto é, como, as transformações mundiais recentes reabrem esse debate sob outra ótica, conduzindo a novas formulações teóricas. Como pano de fundo dessa proposição, levanta a hipótese de que a partir da "periferia" do sistema social, onde os conflitos sociais se apresentam concretamente em sua pluralidade, o analista encontra-se numa perspectiva que lhe permite visualizar melhor os problemas, o que nem sempre resulta em sistematização dos mesmos. Ainda, sugere que a preocupação com o processo social de excludência levou a denominada escola paulista de sociologia a valorizar a análise do processo de socialização como eixo fundamental da formação da identidade, principalmente nas pesquisas so-
${ }^{16}$ Nadia Urbinati sugere a presença desse procedimento em Gramsci que, ao debater a questão meridional, busca apontar antes as fraquezas da sociedade italiana como um todo do que os problemas exclusivos da região sul do país. Ver: URBINATI (1996) 
bre a questão racial no Brasil. Como a socialização é retomada pelas modernas análises sobre a sociedade, levanta a hipótese da atualização de vários pontos daquele projeto de pesquisa coletivo, que envolveu Florestan Fernandes e seus assistentes.

\section{Referências bibliográficas}

ARRUDA, Maria Arminda do Nascimento (2001) Metrópole e cultura. São Paulo no meio século XX. Bauru, SP: EDUSC.

BERLINCK, Manoel T. (1975) Marginalidade social e relações de classes em S. Paulo. Petrópolis: Vozes, p. 13-42.

BOCK, Kenneth (1980) "Teorias do Progresso, Desenvolvimento e Evolução". In: Tom BOTTOMORE e Robert NISBET, (org.). História da análise sociológica. Rio de Janeiro: Zahar Editores, p. 65-117.

CASANOVA, Pablo González (1969) Sociologia de la explotación. México: Siglo Veintiuno.

CHARTTERJEE, Partha (1993) The Nations and its Fragments. Princeton: Princeton University Press.

COSTA PINTO, L. A. . "Panorama geral”. In: L.A.COSTA PINTO e Edison CARNEIRO. As Ciências Sociais no Brasil. Rio de Janeiro: CAPES, Série Estudos e Ensaios - 6 -, p. 39.

(1960). "Introdução". In: Anais do Seminário Internacional Resistências às Mudanças - fatores que impedem ou dificultam o desenvolvimento. Rio de Janeiro: Centro Latino-Americano de Pesquisas em Ciências Sociais, publicação n. 10, p.7.

DESAL (1966) América Latina y desarrollo social. $2^{\mathrm{a}}$ ed. Santiago de Chile: 
Herder, p. 75-77.

FERNANDES, Florestan (1976) A Sociologia no Brasil: contribuição para o estudo de sua formação e desenvolvimento. Petrópolis: Vozes, p. 53-54.

(1974) Mudanças sociais no Brasil. São Paulo: Difusão Européia do Livro,

(1960a) “Atitudes e motivações desfavoráveis ao desenvolvimento". In: Anais do Seminário Internacional Resistências às Mudanças - fatores que impedem ou dificultam o desenvolvimento. Rio de Janeiro: Centro LatinoAmericano de Pesquisas em Ciências Sociais, publicação n. 10, p. 219-259.

(1945) “Tarefas da inteligência”. In: Folha da Manhã, 3 de março.

(1960b) "Existe uma crise da democracia no Brasil?" In: Revista Anhembi, ano IV, v. XVI, n. 48, 1954; Mudanças sociais no Brasil. São Paulo: Difel, 1960.

LAMBERT, Jacques (1960) "Les obstacles au dévelloppement provenant de la formation d'une société dualiste. In: Anais do Seminário Internacional Resistências às Mudanças - fatores que impedem ou dificultam o desenvolvimento. Rio de Janeiro: Centro Latino-Americano de Pesquisas em Ciências Sociais, publicação n. 10, p. 27-50.

LINHARES, M. Yedda \& TEIXEIRA DA SILVA, Francisco C. (1981) História da Agricultura Brasileira: combates e controvérsias. São Paulo: Brasiliense, p. 40.

MARTINS, José de Souza (1997) Exclusão social e a nova desigualdade. São Paulo: Paulus.

MARTINS, Tatiana Gomes (2008) Florestan Fernandes e Guerreiro Ramos - para além de um debate. Tese de Doutorado. Campinas: PPGSociologia/ Ifch/UNICAP. 
MICELI, Sergio (1989) História das Ciências Sociais no Brasil. Volume 1. São Paulo, Vértice, Editora Revista dos Tribunais, IDESP, p. 73.

MILLS, C. Wright (1960) "Remarks on the problem of industrial development". In: Anais do Seminário Internacional Resistências às Mudanças - fatores que impedem ou dificultam o desenvolvimento. Rio de Janeiro: Centro LatinoAmericano de Pesquisas em Ciências Sociais, publicação n. 10, p. 281-287.

NOBRE, Marcos (2003) "Luta por reconhecimento: Axel Honneth e a Teoria Crítica". In: Axel HONNETH. Luta por reconhecimento. A gramática moral dos conflitos sociais. São Paulo: Editora 34, p. 9.

QUIJANO, Aníbal (1966) Notas sobre el concepto de marginalidad social. Santiago, Chile: CEPAL.

SCHWARCZ, Lilia Moritz \& BOTELHO, André (2011) Simpósio: cinco questões sobre o pensamento social brasileiro. In: Lua Nova. Revista de cultura e política. São Paulo: CEDEC, n. 82, p.139-159.

STAVENHAGEN, Rodolfo (1974) Sociología y subdesarrollo. $2^{\text {a }}$ ed., México: Editorial Nuestro Tiempo

URBINATI, Nadia (1996) "Le passione e La politica. Il Meridione di Antonio Gramsci”. In: Studi Storici, ano 37, abr/jun. Roma: Istituto Gramsci, p. 465-487.

VEKEMANS, Roger \& FUENZALIDA, Ismael Silva (1969) "El concepto de marginalidad". In: DESAL. Marginalidade en América Latina: um ensayo de diagnóstico. Barcelona: Herder, p. 44.

VILLAS BÔAS, Glaucia (2006) Mudança provocada - passado e futuro no pensamento sociológico brasileiro. Rio de Janeiro: Editora FGV.

(2005) "Por que rever mais uma vez o conceito de marginalidade estrutural de L. de A. Costa Pinto?". In: Perspectivas, São Paulo, v.28, jul./dez, p. 79-103. 